\title{
Publisher's Comment
}

\author{
Gary W. Schnitz
}

Welcome to the Journal of Biocommunication issue 43-1. The issue represents our first issue of 2019, and our sixth issue designed for our new mixed publishing format offering authors traditional publishing and open access options.

Our professions only progress when information is shared or communicated. Our Journal's mission is to do just that. Please consider submitting a manuscript.

\section{OPEN ACCESS}

\section{Introduction}

The Journal Management Board is proud to publish $J B C$ issue $43-1$. We present three articles, along with our usual columns, Showcase, and Gallery.

\section{Years Ago in the $J B P A / J B P$}

Thomas St. John Merrill offers his column, "25 Years Ago in the JBPA/JBP," as a look back at the legacy technology, photographic techniques, and equipment from years past. Thomas combines his reflective discussion of these articles with some of his own personal insight.

Thomas reviews JBP Volume 63, Numbers 1 through 4 that include content published by authors: Leon LeBeau, Kenneth Michaels, Barbara Katzenberg, Anne Shiras, Bryan Hardesty, Lewis Koster, Susanne Loomis, Will Renner and C. Allen Schaffer, Michael Morris, and William Young.

Thank you, Thomas, for continuing to help our professions move forward by better understanding our past.

\section{Medical Photography: Practices of Graduate Students at Makerere University}

This study comes to the $J B C$ from authors at
Makerere University College of Health Sciences (Uganda). The article delineates trends in medical photography practices among graduate students at Makerere University in Kampala, Uganda. The authors' data suggests that most graduate students at their institution first encounter medical photography in their classes, although some had taken their own medical photographs primarily using their mobile phones.

\section{Usability Guidelines for an Online Image Database}

In this article, authors Chang, Bliss, and Altemus review online images databases. The authors used established usability design principles to develop a set of 50 recommendations for improving database organization, navigability, and search functionality.

The authors conduct a resource audit of commercial and non-profit image galleries that are available and evaluate them upon established criteria. The findings of this study are summarized within a spreadsheet that can be used as reference for prospective image databases in the future. A link to this downloadable XML file can be found on the 43-1 Table of Contents adjacent to the article.

\section{Developing a Virtual Lab to Teach Essential Biology Laboratory Techniques}

Authors Miyamoto, Milkowski, Young, and Lebowicz present "Developing a Virtual Lab to Teach Essential Biology Laboratory Techniques." In this project, a virtual lab for preparing a phosphate-buffered saline solution (PBS) was created to educate undergraduate biology students on essential laboratory techniques. The virtual lab being presented in this article included animations and interactive elements to visually communicate each step. 


\section{Showcase}

Our 43-1 Showcase recognizes the accomplished work of AMI member Bill Andrews, who was the recipient of AMI's 2018 Lifetime Achievement Award.

This represents AMI's most significant award and is presented annually to an AMI member who has dedicated his or her professional life as a medical illustrator.

Bill currently serves as Chair of the Department of Medical Illustration, College of Allied Health, Augusta University. His teaching responsibilities have evolved over time, teaching traditional medical illustration techniques, as well as electronic media and multimedia courses. Bill also has developed a rigorous business practice course designed to prepare students for life beyond the university. In 2009, Bill became the youngest educator to win the AMI Brödel Award for Excellence in Education.

\section{Gallery}

The $J B C$ Gallery for this issue includes 54 award winners from AMI's 2018 Salon exhibition from Newton, Massachusetts. We hope that you will take another look at these award-winning illustrations, animations, and interactive media entries.

\section{Your Feedback is Appreciated}

We rely on our readers for feedback about the Journal, and we invite you to share your thoughts with us about any of our columns and articles. We always appreciate your suggestions for improvement. We also encourage you to submit manuscripts for publication.
For a complete list of $J B C$ Management Board members, Editors, and Advisors, visit: http://jbiocommunication.org/management.html

Gary Schnitz, Chair and Co-editor Journal of Biocommunication Management Board

\section{Licensing}

The author has chosen to license this content under a Creative Commons Attribution, NonCommercial, NoDerivatives 4.0 International License.

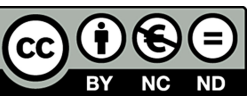

